provocateurs have been used, posing as guerrillas in need of treatment, to determine the "loyalty" of the psychiatrists.

According to Dr Bermann, when first arrested, he was himself tortured in an attempt to establish a link between him and the guerrillas. When the authorities finally realised that he had no information to give them, he was put in a cell with other "political prisoners who knew nothing," from which the sounds of others being tortured could be heard.
Dr Bermann, as a professor and former director of a psychiatric clinic, ranked as an important prisoner-and as such was chosen as a kind of hostage when President General Jorge $\mathbf{H}$. Videla visited Cordoba last year. Twenty such hostages were arrestedthough as incommunicado prisoners they could do nothing to avert any possible attack on the presidential party. Nevertheless, their fate depended on the safety of the President and his entourage, according to an equation which seems to be a peculiarly Argentinian way of assessing the value of its leading citizens.

If there was any attempt on the President's life, they were told, all 20 would be shot; if a General was killed, 14 would be shot, if a colonel, eight, and if any other official or policeman were killed, only two. So, by the new Argentinian mathematics, it would appear that one leading psychiatrist equals half a policeman!

Vera Rich

\title{
US producers fear ban on 2,4,5-trichlorophenol
}

SOME of the producers of 2,4,5-trichlorophenol fear that it might be banned in the US. The Environmental Protection Agency (EPA) has recently issued a notice of 'rebuttal presumption' against current and continued registration of trichlorophenol and its salts. The notice-the first of several which the agency intends to issue-says that they exceed "certain risk criteria".

The issuing of a rebuttal presumption is not, says the agency, notice of intent to ban the products. Such action would only be taken after careful evaluation of all the evidence had shown that their continued use would cause "unreasonable adverse effects to the environment". However, the notice does require that the users and manufacturers of trichlorophenol submit evidence to the EPA, proving that its continued use does not constitute a hazard.

This is not the first time that the EPA has reviewed these particular chemicals. 2,4,5-trichlorophenol is used in the manufacture of the herbicide 2,4,5-trichlorophenoxyacetic acid $(2,4,5-T)$ and of the bacteriacide, hexachlorophene. The reaction process used to make trichlorophenol produces an extremely toxic by-product, tetrachlorodibenzo-p-dioxin (TCDD). It is the presence of TCDD-a known teratogen and potential carcinogenwhich is causing the current concern.

$2,4,5-\mathrm{T}$ has been reviewed recently by government committees in the UK and Australia; both review bodies pronounced the herbicide safe if used for the purposes for which it is intended. Manufacturers are less optimistic about its chances in the US.

Among the most recent evidence that the EPA will examine are two sets of documents relating to the safety of the manufacturing process. The first is the Italian Parliamentary Commission's report of its investigation into the accident which occurred in the ICMESA trichlorophenol reactor near the Italian town of Séveso nearly two years ago. The second is the report of ICMESA's Swiss owners, Givaudan and Hoffman-La Roche, on their own research into the cause of the accident.

Their report is in reply to the commission, but it has been prepared especially for the EPA. The commission's report, which runs to several hundred pages, accuses Roche and Givaudan of being less than candid about their operations at ICMESA and of running an unsafe chemical plant. The commission also claims that ICMESA was producing trichlorophenol without an up-to-date 'fire precautions certificate'; that it failed to inform the Labour Inspectorate that it had begun production of trichlorophenol; that it failed to notify the authorities of the accident for twenty-seven hours; and that when it did inform them, no mention was made of the release of TCDD.

ICMESA produced 130 tons of trichlorophenol in 1975 and 1976; a sizeable amount, according to the Italian commission. Roche and Givaudan will contend in their report that compared to the output of companies in the US and Germany this is a small amount. The commission's suggestion that the trichlorophenol reactor was poorly designed, is refuted by Givaudan, who claim that their design incorporated all the features necessary at the time for safe reactor operation.

The ICMESA reactor did not incorporate a dump tank to collect unwanted discharges from the reactor vessel. Givaudan thought this unnecessary, in view of the plant's other safety features. The commission, however, thinks this was a serious error.
A safety disc on the vessel was designed to rupture at the pre-set pressure of 3.5 atmospheres, and so discharge TCDD over Séveso. The Italian report states that a lower value would have caused a rupture at a less advanced stage of the reaction, with less disastrous consequences. Givaudan argue that the disc was incorporated to cope with mishaps at the beginning of the trichlorophenol reaction process - the accident at Séveso happened some six hours after the reaction was completed-and that the rupture pressure of the disc was selected for sound chemical reasons.

Central to the concern about the health of Séveso's inhabitants is the two week delay in their evacuation from TCDD contaminated areas. The commission says that Roche and Givaudan did not act swiftly enough to determine the extent of contamination. The companies contend that after a map of the polluted area had been made - a task which took two weeksthe proper authorities were informed and recommended by Roche to evacuate the area. Roche says that the authorities resisted initially until they appreciated the gravity of the situation.

Many scientists think the Séveso residents were exposed to low levels of TCDD. The commission disagrees, and recommends further studies to assess the long-term effects to health. TCDD is a potential carcinogen, and numerous scientists consider such studies essential. The International Agency for Research on Cancer (IARC), which has recently published a new report on the polychlorinated dibenzodioxins is currently assessing the chemicals' carcinogenicity. It is reviewing evidence from a number of the fourteen accidents which have occurred in trichlorophenol plants since 1949.

Alastair Hay 